\title{
Formation of integrated structural units using the systematic and integrated method when implementing high-rise construction projects
}

\author{
Ivan Abramov ${ }^{1, *}$ \\ ${ }^{1}$ Moscow State University of Civil Engineering, 26 Yaroslavskoe shosse, Moscow, 129337, Russia
}

\begin{abstract}
Development of design documentation for a future construction project gives rise to a number of issues with the main one being selection of manpower for structural units of the project's overall implementation system. Well planned and competently staffed integrated structural construction units will help achieve a high level of reliability and labor productivity and avoid negative (extraordinary) situations during the construction period eventually ensuring improved project performance. Research priorities include the development of theoretical recommendations for enhancing reliability of a structural unit staffed as an integrated construction crew. The author focuses on identification of destabilizing factors affecting formation of an integrated construction crew; assessment of these destabilizing factors; based on the developed mathematical model, highlighting the impact of these factors on the integration criterion with subsequent identification of an efficiency and reliability criterion for the structural unit in general. The purpose of this article is to develop theoretical recommendations and scientific and methodological provisions of an organizational and technological nature in order to identify a reliability criterion for a structural unit based on manpower integration and productivity criteria. With this purpose in mind, complex scientific tasks have been defined requiring special research, development of corresponding provisions and recommendations based on the system analysis findings presented herein.
\end{abstract}

\section{Introduction}

Competent HR management ensures higher labor productivity and enhanced reliability of structural units resulting in maximum avoidance of negative developments in the course of implementation of a high-rise construction project (1).

Payroll usually accounts for about $30-40 \%$ of total project costs [2], while manpower is deemed to be a decisive resource of any project as a factor contributing to improved productivity and reliability of the business $[3,4]$.

\footnotetext{
${ }^{*}$ Corresponding author: ivan@yandex.ru
} 
Labor productivity (5) is a critical factor of labor cost efficiency. Its level is characterized by the ratio of the volume of completed work to the time spent on its completion. The labor productivity level determines:

Pace of construction;

Revenues of all parties involved in the project;

Cost reduction per square meter.

An important part of construction planning is formation of construction crews staffed depending on particulars of the future construction project and the objectives to be achieved.

These objectives include pursuance of research focused on formation of integrated construction crews at the stage of designing organizational and technological construction processes.

A major contribution to defining and finding solutions to designing organizational and technological construction process-related tasks, including those to be implemented by construction crews, has been made by the following research:

The authors of works [6-9] review efficiency potential models for organizational and technological solutions of a construction project that make it possible to take into account the impact of organizational, technological and managerial solutions in the implementation of a construction project expressed by various factors.

The authors of works [10-13] suggest an approach to tackling the optimization task of resource distribution in the planning of construction and installation works. The resource under review is manpower (crews) with its sufficiency and work load determining the duration of works as a critical planning factor.

Case study [14] offers a quantity assessment methodology for factors affecting labor productivity in masonry construction, including compatibility, conformance to requirements and professionalism.

The authors of work [15] argue that the productivity growth does not depend on fulfilment of as many tasks as possible irrespective of the time schedule, a greater workload or the number of work hours spent.

Productivity improves subject to a more predictable work schedule allowing for a better coordination between work load and the available capacities (man-hours).

\section{Findings and Discussion}

The author has used his analysis and research findings to develop a model that simulates significant factors affecting the final outcome and identifies a reliability factor of a structural unit based on the integration and production values of the construction crew under review. These significant factors affecting the final outcome include qualification, professional training, experience, productivity, labor condition management, violations of labor discipline, and coordination of production processes performed by various crews.

Unlike the analyzed works and research, this paper reviews a systematic and integrated method to determine the impact of the identified integration and production factors of a construction crew on the reliability of a structural unit.

\section{Methods}

A great diversity of high-rise construction projects are being undertaken in Russia with unique requirements set to structural units responsible for various project stages (Fig. 1). 
Requirements to structural units include:

Conformity of the type of labor resources (crews) to the content and sequence of the works to be performed

Conformity of the number, specialization and grades of workers to the scope, content and complexity of the works to be performed

Ensuring continuity of working processes, multi-skilling possibilities and application of sound working methods and practices

Ensuring maximum integration in the performance of works by a crew

Enhancing labor productivity of an integrated crew

Reliability of a structural unit

Fig.1. Diversity of high-rise construction projects

To begin with, let us focus on the requirements of ensuring maximum integration in the performance of works by a crew and enhancing labor productivity.

Formation of integrated construction crews supported by corresponding research into

factors affecting the productivity of these structural units is a vital task.

The author has developed an algorithm for accomplishing this task that can be

schematically represented as follows:

- Identification of factors affecting the integration of a crew as an element of a structural construction unit;

- Assessment of the factors;

- Development of an instrument for defining a measure of integration of an element of a structural construction unit, in particular, a crew;

- Identification of factors affecting the productivity of structural construction units;

- Assessment of the factors;

- Development of an instrument for defining a measure of productivity of an element of a structural construction unit, in particular, a crew;

- Determination of the factors' impact on the final outcome of the works;

- Assessment of the findings of research with the reliability of the structural unit used as the main criteria.

Based on an expert survey, let us identify and describe the main factors affecting integration of a crew:

- $\quad$ Number of interchangeable workers (A);

- $\quad$ Professional levels of workers (B);

- $\quad$ Proficiency of workers in various occupations (C);

- $\quad$ Working time lost in transfer of workloads between workers or units (D);

- $\quad$ Degree of combination of production processes performed by units or workers (F).

Having assessed the factors affecting the outcome (FAR):

$\begin{array}{llllll}\text { Description } & \text { A } & \text { B } & \text { C } & \text { D } & \text { F } \\ \text { Factor's weight } & \text { from }-2 & \text { from }-3 & \text { from }-2 & \text { from }-2 & \text { from }-1\end{array}$



to +2
to +3
to +2
to +2
to +1

We can determine a measure of integration of an integrated construction crew Icc calculated using the following formula:

$$
\mathrm{Icc}=k \sum_{i=1}^{n} V_{i}=k\left(V_{1}+V_{2}+\ldots+V_{n}\right),
$$

where $V_{i}$ is an aggregate $\mathrm{FAR}$, and $\mathrm{k}$ is a coefficient reflecting recommendations of former employers.

Assessment of integration:

$-10 \leq$ Icc $\leq 0$ - this crew is excluded from the project;

$0<$ Icc $\leq 3-$ this crew has little chances of participation in the project;

$4<$ Icc $\leq 6-$ this crew has moderate chances of participation in the project;

$7<$ Icc $\leq 10-$ this crew has the highest chances and priority of participation in the project.

Having determined the measure of integration of a construction crew in accordance with the developed algorithm $[16,17]$, we proceed with the task of determining its productivity.

Research and experience of previous projects have identified the following main factors affecting the productivity of an integrated construction crew:

- $\quad$ Labor distribution within the crew (A): competent placing of workers by the construction manager according to their qualification levels and skills;

- Interchangeability (B): ability to employ workers at any working areas in the event of unforeseen circumstances or upon completion by these workers of their scope of works;

- Human factor - compatibility (C): workers have various individual characteristics, and if they don't find a common language, this may lead to lower productivity of their work;

- $\quad$ Suitability (D): workers have various specializations and can be employed with a higher efficiency in construction of any type of buildings or structures;

- $\quad$ Qualification (F): qualification levels of workers. Workers are able to perform the main types of works at a level conforming to their qualification;

- $\quad$ Self-organization (I): performance of the scope of works irrespective of whether any managerial staff (engineers, technicians or the construction manager) are present on the construction site or not.

Having listed the main requirements to a construction crew and having established a link with the expert assessment, we can rank the factors affecting the final outcome (FAR') as follows:

$\begin{array}{lllllll}\text { Description } & \text { A } & \text { B } & \text { C } & \text { D } & \text { F } & \text { I } \\ \text { Factor's weight } & \text { from }-3 & \text { from }-2 \text { to } & \text { from }-2 & \text { from }-2 \text { to } & \text { from }-1 \text { to } & \text { from }-1 \text { to } \\ & \text { to }+3 & +2 & \text { to }+2 & +2 & +1 & +1\end{array}$

The above analysis should be followed by an assessment of integrated crews using a mathematical model. The productivity indicator of an integrated construction crew Ipcc is calculated according to the following formula:

$$
\mathrm{Ipcc}=k \sum_{i=1}^{n} W_{i}=T\left(V_{1}+V_{2}+\ldots+V_{n}\right)
$$

where $W_{i}$ is an aggregate $\mathrm{FAR}^{\prime}$, and $\mathrm{T}$ is a coefficient reflecting recommendations of former employers.

Assessment of productivity:

$-11 \leq$ Ipcc $\leq 0-$ this crew is excluded from the project; $0<$ Ipcc $\leq 4-$ this crew has little chances of participation in the project; $4<$ Ipcc $\leq 8-$ this crew has moderate chances of participation in the project; 
$8<$ Ipcc $\leq 11-$ this crew has the highest chances and priority of participation in the project.

It should be noted that the productivity and integration indicators of a construction crew require development of an instrument to measure the reliability level of a structural construction unit.

Based on the undertaken research and having determined the productivity and integration indicators of a construction crew, let us find a common indicator of reliability of a structural unit depending on the identified productivity and integration indicators.

Let us introduce a reliability indicator $\mathrm{R}$ reflecting reliability of a structural unit in general. According to Academician A. A. Gusakov(18), "Organizational and technological reliability (OTR) is the ability of organizational, technological and managerial economic solutions to ensure attainment of the targeted outcome of construction in the conditions of random disturbances inherent to construction as a complex probabilistic system". As we can see, $\mathrm{R}$ should depend directly on integration and productivity of a crew. The higher the integration indicator, the more consolidated and harmonious is the crew. This has an obvious positive impact on the reliability indicator. As far as the productivity of a crew is concerned, the more skilled the crew members are, the greater impact it has on the reliability indicator of the structural unit in terms of the quality and duration of works.

Consequently, we can describe reliability as follows:

$$
R=f\left(C_{1} * C_{C C}+C_{2} * I_{p c c}\right)
$$

where $C_{1}$ and $C_{2}$ are some positive real number constants that reflect the distinct proportionate impact of both integration and productivity of a crew on the reliability of a structural unit. In our model, we proceed from $C_{1}=1 / 10$ and $C_{2}=1 / 11$, as the impact of both of these factors on reliability is assumed as being equal.

The f function has a positive first-order derivative over the whole segment, as the higher the linear combination, the greater is the reliability. Also, the function has a negative secondorder derivative over the whole segment, as the growth of productivity and integration leads to a decreasing effect versus scale. In other words, if reliability and integration are high, an increment of the functional argument will produce a lesser effect compared to a situation of low reliability and integration. This is due to the fact that an increase in integration or reliability of an element of a highly reliable structural unit produces a limited effect only. If the reliability factor $\mathrm{R}$ of a structural unit is low, an increase of the above-mentioned indicators will boost reliability to a great extent. This function $\mathrm{f}$ can be assumed as follows:

$$
f(x)=100 * \operatorname{sgn}(x) * \sqrt[3]{|x|}
$$

which meets all conditions described above.

$$
\begin{gathered}
f(x)=100 * \operatorname{sgn}(0.25) * \sqrt[3]{|0.25|}=62.9 \\
f(x)=100 * \operatorname{sgn}(0.5) * \sqrt[3]{|0.5|}=79.3 \\
f(x)=100 * \operatorname{sgn}(1) * \sqrt[3]{|1|}=100 \\
f(x)=100 * \operatorname{sgn}(1.5) * \sqrt[3]{|1.5|}=114.4 \\
f(x)=100 * \operatorname{sgn}(2) * \sqrt[3]{|2|}=125.9
\end{gathered}
$$

The graph of this function is shown Fig. 2. 


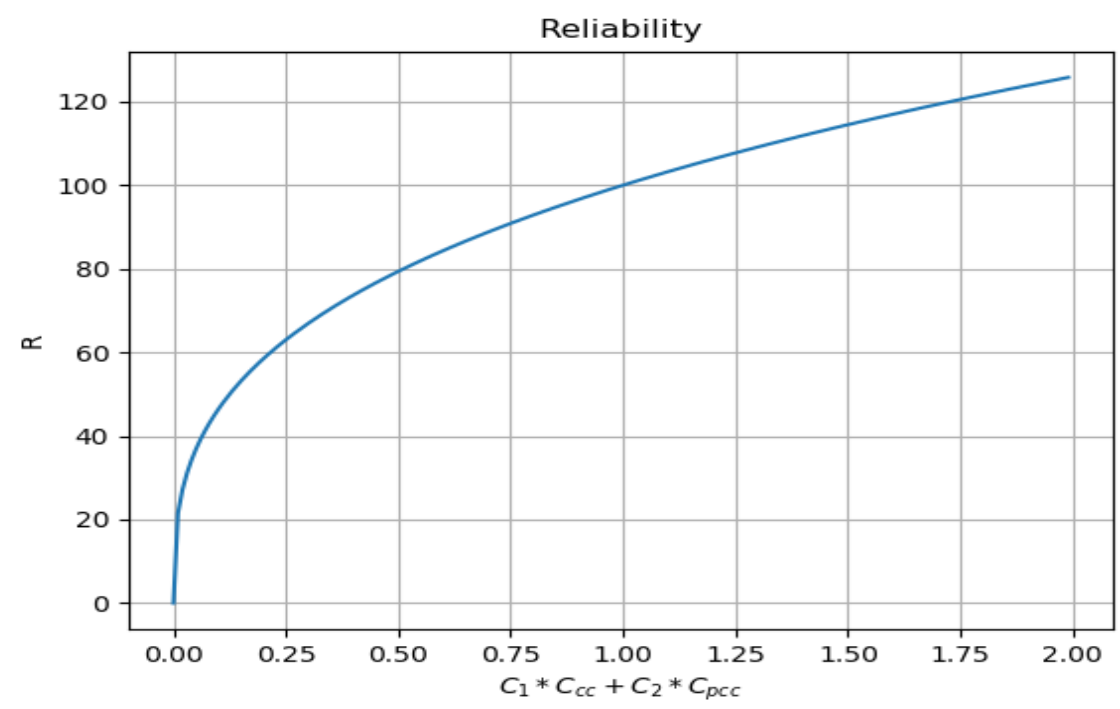

Fig. 2 The graph of function

Diminishing return can be illustrated by the following example:

With Icc $=1$ and Ipcc $=2$, the argument of this function is equal to 0.282. An increment of each indicator makes this argument equal to 0.473 . As a result, the reliability function grows approximately by 12.34 . With Icc $=9$ and Ipcc $=10$, the argument is equal to 1.81 . An increment of both indicators makes it equal to 2 . In this case, the reliability function grows approximately by 4.12. This is an evidence of decreasing returns of the scale. Also, with Icc $=6$ and Ipcc $=7$, an increment of each indicator brings us to the "top" group and makes the reliability grow by 5.26. It means that in order to enter the "top" group, we need a greater growth of reliability as compared to that required in a situation within that group.

For the reliability factor to be within the range of 0 to 100 , we can additionally divide the function into $f(2)$.

\section{Conclusions}

The reliability factor of a structural construction unit has an impact on the resultant qualitative characteristics of a high-rise construction project such as duration, quality and other technical and economic indicators.

This article offers theoretical recommendations and scientific and methodological provisions of an organizational and technological nature for competent formation of integrated construction crews with the purpose of enhancing their productivity and identifying a reliability criterion of their parent structural units.

\section{References}

1. A. Kazaz, S. Ulubeyli, Building and Environment, 42, 2132-2140 (2007).

2. K. Harmon, B. Cole, Construction Briefings, 8, 1-19 (2006).

3. M. Liu, G. Ballard, W. Ibbs, Journal of Management in Engineering, 27, 236-242 (2011).

4. S. AbouRizk, P. Knowles, U. Hermann, Journal of Construction Engineering and 
Management, 127, 502-511 (2001).

5. L. Floreza, J. Cortissoz, Procedia Engineering, 164, 42-48 (2016).

6. A. Lapidus, M. Yershov, P. Oleynik, et al, Technology and Organization of Construction, 4, 6-11 (2014).

7. A. Lapidus, I. Abramov, Organizational and process-related design of private low-rise construction projects when developing a calendar plan, Science Bulletin, 4 (2017).

8. A. Lapidus, A. Berezhnyi, Bulletin of the Moscow State University of Civil Engineering, 3, 149-153 (2012).

9. A. Lapidus, I. Abramov. Science review, 4, 6-9 (2017).

10. V. Mishchenko, D. Yemelyanov, A. Tikhonenko, Voronezh State University Architecture and Civil Engineering, 6, 76-78.

11. V. Mishchenko, D. Yemelyanov, A. Tikhonenko, Industrial and Civil Engineering, 10, 69-71 (2013).

12. V. Mishchenko, E. Gorbaneva, Y. Rithy, F. Lin, Application of the flow method in low-rise urban residential development in hot climates, Ho Chi Minh City University of Architecture, 28-38.

13. P. Oleynik, V. Grigoriev, Technology and Organization of Construction, 2, 42-44 (2014).

14. L. Floreza, J. Cortissoz, Procedia Engineering, 164, 42-48 (2016).

15. A. Fini, T. Rashidi, Journal of Construction Engineering and Management, 142 (2015).

16. A. Lapidus, I. Abramov, Science Review, 9 (2017).

17. I. Abramov, T. Poznakhirko, A. Sergeev, The analysis of the functionality of modern systems, methods and scheduling tools, MATEC Web of Conferences, 86 (2016).

18. A. Gusakov, System techniques in construction, ASV Publishers (2004).

19. P. Oleynik, V. Brodskiy, Technology and Organization of Construction, 2, 40-43 (2013).

20. P. Oleynik, V. Brodskiy, Technology and Organization of Construction, 3, 35-38 (2013).

21. P. Oleynik, V. Grigoriev, Technology and Organization of Construction, 2, 42-44 (2014).

22. P. Oleynik, V. Brodskiy, Technology and Organization of Construction, 2, 40-43 (2013).

23. A. Lapidus, A. Makaraov, Bulletin of the Moscow State University of Civil Engineering, 8, 150-160 (2015).

24. V. Mischenko, D. Yemelyanov, A. Industrial and civil construction, 10, 69-71 (2013).

25. A. Lapidus, T. Bidov, International Journal of Applied Engineering Research, 11 (2016). 